\title{
ОСОБЫЕ ЭКОНОМИЧЕСКИЕ ЗОНЫ КАК ИНСТРУМЕНТ РАЗВИТИЯ НАЦИОНАЛЬНОЙ ЭКОНОМИКИ'
}

\section{SPECIAL ECONOMIC ZONES AS A TOOL FOR DEVELOPMENT OF THE NATIONAL ECONOMY}

\section{R. Fattakhov \\ O. Pivovarova \\ D. Morkovkin}

Summary: The article presents analysis of the development of special economic zones in national economies of different countries. The authors examine how the creation of such zones in a specific area contributes to accelerated economic growth. The study systematized conceptual approaches to the creation of such territories around the world in accordance with the level of their economic development. It has been found that nowadays only a limited number of countries systematically evaluates the effectiveness of special economic zones, the level of their positive impact on the national economy of the country, and applies mechanisms to combat the lack of effectiveness of the economic development.

Keywords: special economic zone, territories with a special legal status, economic growth, national economy, regional development.
Фаттахов Рафаэль Валиахметович

Ә.э.н., г.н.с., професссор, Финансовый университет при Правительстве Российской Федерации (г. Москва)

RFattakhov@fa.ru

Пивоварова Ольга Владимировна

Н.с., Финансовый университет при Правительстве Российской Федерации (г. Москва) olga_piv@mail.ru

Морковкин Дмитрий Евгеньевич К.э.н., в.н.С., дочент, Финансовый университет при Правительстве Российской Федерации (2. Москва) DEMorkovkin@fa.ru

Аннотация: В статье представлен анализ развития особых экономических зон в национальных экономиках различных стран мира. Авторами обосновано, что создание $0 Э 3$ на определённой территории способствует ускоренному экономическому росту. В ходе исследования была проведена систематизация концептуальных подходов к образованию подобных территорий по странам мира в соответствии с уровнем развития их экономики. Выявлено, что на сегодняшний день ограниченное количество стран систематически оценивают эффективность функционирования особых экономических зон, уровень их позитивного влияния на национальную экономику страны в целом, а также применяют механизмы, позволяющие бороться с недостаточной результативностью исследуемого инструмента развития экономики.

Ключевые слова: особая экономическая зона, территории с особым правовым статусом, экономический рост, национальная экономика, региональное развитие.

\section{$\triangle$ райвер развития экономики в развиваюшихся странах.}

ются особые правовые, организационные и экономические режимы на отдельных территориях с целью проведения активной экономической политики и пространственного развития. Основная идея данного инструмента, заложенная государственной властью, заключается в том, что введение исключений из общего институционального, экономического, правового пространства сможет компенсироваться значительными преимуществами как для соответствующих территорий, так и для национальной экономики в целом. Территории с особым статусом во внешнеэкономической деятельности рассматриваются как фактор ускоренного экономического роста за счет стимулирования международного товарооборота, увеличения инвестиций, трансфера технологиями, информацией и углубления интеграционных экономических процессов.
Китай. Китайские особые экономические зоны (далее - ОЭЗ) возникли в рамках «политики реформ открытости» В начале 1980-х годов. В рамках проведения эксперимента с реформами рыночной экономики особые зоны были образованы в четырех прибрежных городах Шэньчжэнь, Чжухай, Шаньтоу и Сямынь, располагающиеся в относительной близости от Гонконга (Китай), Макао (Китай) и Тайваня (провинция Китая). За ними последовали зоны, созданные в городах вдоль восточного побережья, чтобы полностью использовать географические преимущества этих городов для привлечения иностранных инвестиций [1]. В последствии состоялись две волны расширения программ ОЭЗ с географической направленностью развития новых ОЭЗ вглубь страны и

1 Статья подготовлена по результатам исследований, выполненных за счет бюджетных средств по государственному заданию Финуниверситета 
Свободные экономические зоны государственного уровня в Китае

\begin{tabular}{|l|} 
ПЯть категорий в официальном справочнике \\
\hline - Зона экономического и технологического развития (ETDZ) \\
- Зона высокотехнологичного промышленного развития (HIDZ) \\
- Специальная таможенная зона (SCZ) \\
- Приграничная / трансграничная зона экономического сотрудничества \\
(BECZ) \\
• Другие типы
\end{tabular}

Отдельные типы зон широкого охвата

- Особая экономическая зона

- Новая национальная зона

- Национальная демонстрационная зона инноваций

- Национальная ключевая экспериментальная зона для развития и освоения

- Пилотная зона свободной торговли

- Трансграничная пилотная зона электронной коммерции

Источник: ЮНКТАД на основе Справочника зон развития Китая (Объявление № 4, 2018 год), данных Национальной комиссии развития и реформ, Министерства науки и технологий, Министерства земли и ресурсов, Мини-

стерства жилья и городского хозяйства, Министерства торговли и Главного таможенного управления.

к западу от Китая, что, безусловно, поспособствовало региональному развитию. В официальном справочнике зон 2018 года зарегистрированы пять категорий из 552 зон государственного уровня и 1991 провинциальные зоны, на которые приходится более половины всех ОЭЗ в мире (таблица 1), за исключением ОЭЗ, созданных на местном уровне.

Страны Южной Азии. Индия была одной из первых стран региона, которая приняла программу ОЭЗ еще в 1965 году. Однако, в 1960-х и 1970-х годах программа ОЭЗ практически не реализовывалась. В 2000 году новая программа развития позволила правительствам штатов, а также частному сектору создавать ОЭЗ. Закон ОЭЗ 2005 года был направлен на стимулирование инвестиций частного сектора в поддержку промышленного развития. Этот закон преобразовал специальные экономические зоны (далее - СЭЗ) в ОЭЗ и уточнил правила создания других ОЭЗ, что привело к активному планированию новых зон - хотя многие из них впоследствии были отменены из-за спорных приобретений земли, отсутствия спроса на пространство ОЭЗ, замедления экономического роста и изменений в режиме налоговых льгот для ОЭЗ. В настоящее время в Индии действует 231 ОЭ3, более $60 \%$ из которых специализируются на производстве и услугах, связанных с информационно-коммуникационными технологиями. На сегодняшний день Индия проявляет более осторожный подход к развитию ОЭЗ, отказавшись от стимулов для застройщиков в 2016 году и постепенно сокращая прямые налоговые льготы для арендаторов к 2020 году [2].

Восемь государственных и одна частная СЭЗ в Бангладеш являются специализированными ОЭЗ, ориентированными, в основном, на производство одежды и текстиля. Частная СЭЗ - Корейская зона экспортной переработки, была разработана и управляется дочерней компанией Youngone Corporation (Республика Корея). Помимо девяти СЭЗ в стране расположены еще 30 экономических зон, 24 из которых находятся в стадии формирования.
В ближайшие годы количество ОЭЗ в Южной Азии существенно возрастет. В Индии более 200 новых зон находятся в стадии разработки, хотя темпы роста могут сократиться, поскольку разрешения на значительное количество зон были отозваны. В Бангладеш еще 60 ОЭЗ находятся в процессе утверждения. Пакистан планирует еще 39 ОЭЗ в дополнение к существующим семи. Непал, имеющий две зоны, одна из которых находится в стадии строительства, планирует создать еще 12.

Страны Западной Азии. Турция, которая приняла Закон о свободных зонах в 1985 году, управляет 18 активными свободными зонами и еще одна находится в стадии разработки. В 2000-х годах Турция создала ОЭЗ нового типа - зоны развития технологий - для привлечения инвестиций в научно-исследовательские и высокотехнологичные отрасли. Эти зоны предоставляют налоговые льготы для деятельности, ориентированной на исследования, разработку программного обеспечения и других инноваций [3].

Страны Совета сотрудничества стран Персидского залива используют программы ОЭЗ для поддержки стратегических преобразований в ключевых отраслях. Многие из них построены с государственным участием и оснащены самой современной инфраструктурой. Наиболее яркими примерами являются ОЭЗ в Объединенных Арабских Эмиратах, где первая свободная зона была создана в порту Джебель-Али в 1985 году. Цель заключалась в оказании помощи в развитии порта, который был расположен вдали от населенных пунктов и изо всех сил пытался привлечь бизнес через многонациональные предприятия (далее - МНП) для создания региональных распределительных центров. После успеха порта Джебель-Али в стране распространились ОЭЗ. Многие из свободных зон в Объединенных Арабских Эмиратах действуют как центры реэкспорта. В 2000 году была создана первая неторговая зона, свободная от технологий, электронной коммерции, предназначенная для инвестиций в ряд областей, связанных с услугами в сфере информационных технологий. Впоследствии были созданы другие специализированные свободные зоны, включая 


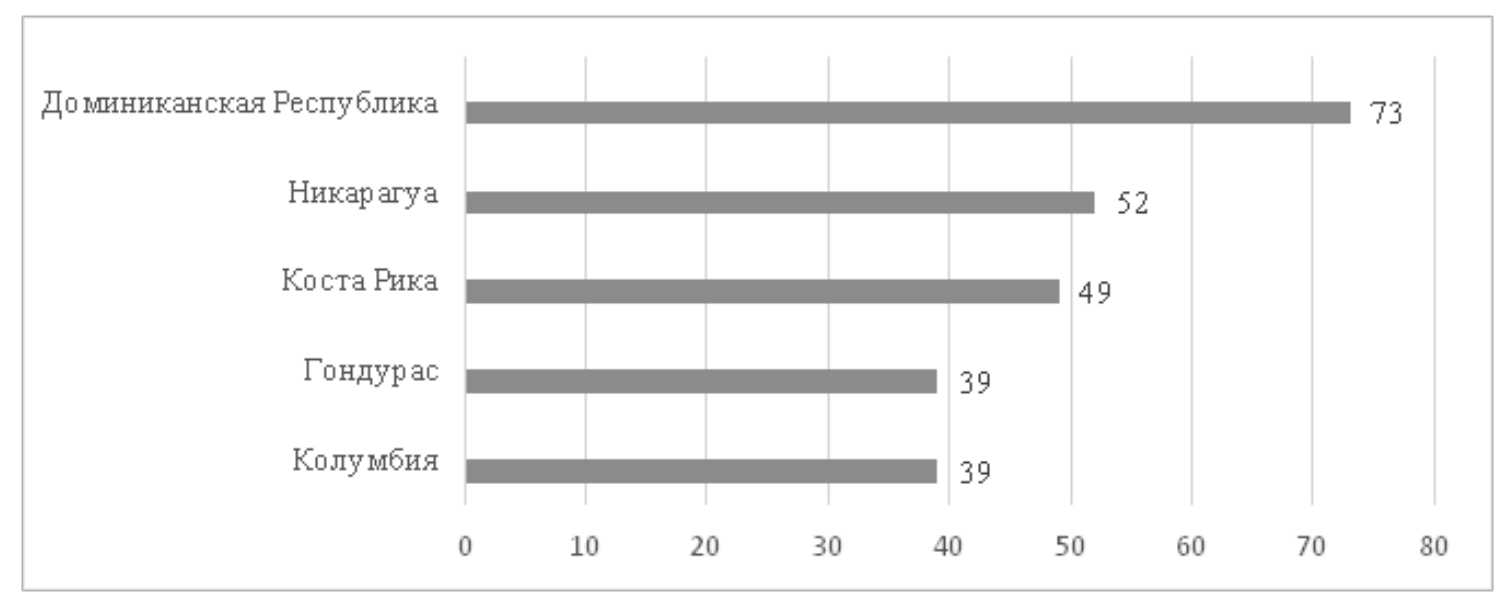

Рис. 1. Страны Латинской Америки и Карибского бассейна с наибольшим количеством ОЭЗ, по данным на 2019 г.

Источник: ЮНКТАД

Dubai Internet City, Dubai Media City, Knowledge Village, Dubai Multi Commodities Centre и Dubai Health Care City.

Страны Латинской Америки и страны Карибского бассейна. Зоны свободной торговли возникли в странах Латинской Америки довольно давно, некоторые из которых были созданы еще в начале 19 века (рисунок 1). ЗСТ Колония и Нуэва Пальмира в Уругвае были созданы в 1923 году. Большинство стран региона разработали свое действующее законодательство об ОЭЗ в 1990-х годах.

Страны с переходной экономикой. За исключением Украины $^{2}$, все страны с переходной экономикой в настоящее время имеют определенную форму ОЭЗ. Российская Федерация, долю которой составляет 70\% ВВП региона, включает более половины из 237 зон региона. В стране сложная сеть зон разного типа: в том числе две глобальные зоны (Калининград и Магадан); 26 ОЭЗ, попадающих под действие закона об ОЭЗ, принятого в 2005 году; Инновационный центр «Сколково», который пользуется привилегиями ОЭЗ в соответствии с законом 2010 года; 100 ТОСЭР в регионах России и моногородах; Свободный порт Владивосток, состоящий как минимум из пяти подзон (портов). В других странах, где масштабы экономики не так значительны (таких, как Северная Македония и Сербия) также размещается много ОЭЗ (15 и 14 соответственно) [4]. Страны с переходной экономикой включают ряд развивающихся стран, не имеющих выхода к морю; поскольку ОЭЗ часто являются неотъемлемыми частями инфраструктурных узлов, как правило, вблизи городских зон, пограничных переходов и транспортных коридоров, они являются излюбленным политическим инструментом стран с низким уровнем экономического развития. Данные ОЭЗ, как правило, ориентированы на общее производство, несмотря на то что в Российской Федерации значительная роль отведена технологически ориентированным зонам. Кроме того, в Российской Федерации размещены 9 туристических зон. Отраслевая направленность ОЭЗ часто отражает промышленные традиции и наличие природных ресурсов у принимающих стран [5].

Следует отметить, что в значительной части стран с переходной экономикой городские и внутрирегиональные ОЭЗ доминируют из-за отсутствия выхода к морю. Собственность на территории ОЭЗ часто является частной, однако большинство зон имеют статус государственной собственности. Зарубежные операторы имеются в Беларуси (в китайско-белорусском индустриальном парке «Великий камень»), в Армении (высокотехнологичный альянс СЭЗ в Ереване управляется российской компанией «Ситроникс») и в Грузии (свободная индустриальная зона Хуалинг Кутаиси управляется китайской фирмой) [6].

\section{Авигатель нашиональной экономики в странах с развитой экономикой.}

ОЭЗ находятся примерно в 70\% развитых стран. Почти все зоны являются беспошлинными зонами, и их экономическое значение для общей экономики страны, в которой они расположены, относительно ограничено, за исключением, Соединенных Штатов Америки. На зоны внешней торговли в этой стране приходится более 70\% зон всех развитых стран (рисунок 2). В большинстве европейских стран нет ОЭЗ или присутствуют только таможенные зоны [7]. Однако в Болгарии, Литве и Польше есть как беспошлинные зоны, так и зоны, в которых предлагаются другие налоговые льготы.

Общая направленность экономической политики в

2 Преференции зон на Украине были отменены в середине 2000-х годов, а зоны были официально закрыты в 2016 году. 


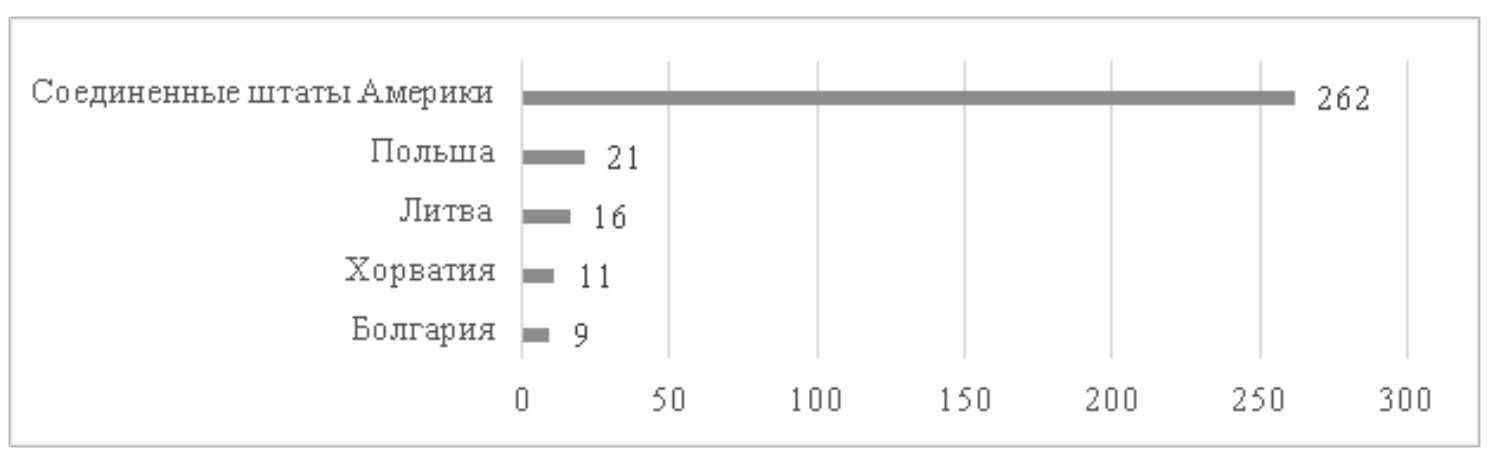

Рис. 2. Развитые страны с наибольшим количеством ОЭЗ, по данным на 2019 г.

развитых странах заключается в создании равных условий в экономике, а не в создании привилегированных районов. Основным обоснованием создания ОЭЗ в развитых странах является снижение искажающего воздействия тарифов и издержек, связанных с импортом.

Правительства некоторых стран с развитой экономикой оказывают помощь в создании разнообразных парков науки и техники. Однако, участие правительства чаще всего принимает форму капитальных расходов, а не налоговых или других законодательных стимулов, обусловленных размещением в конкретных зонах [8]. Региональное развитие или поддержка слаборазвитых районов или районов с высоким уровнем безработицы также служит обоснованием для создания ОЭЗ в развитых странах. Япония и Польша применяют стимулы для инвесторов в менее развитых регионах страны через механизмы ОЭ3. Зоны предпринимательства в Соединенном Королевстве и свободные городские зоны во Франции являются другими примерами таких зон, которые, однако, не функционируют как особые экономические зоны с отдельными режимами регулирования.

ОЭЗ в Соединенных Штатах, известные как зоны внешней торговли, являются зонами, свободными от таможенных пошлин. Цель этих зон состоит в том, чтобы побудить фирмы осуществлять дистрибуцию или производственные операции на предприятиях США, а не где-либо еще. Внешнеторговые зоны освобождают от тарифов и таможенного административного бремени, что ставит США в невыгодное положение по сравнению с конкурентами из-за рубежа. Преимущества распространяются на местные фирмы без необходимости их перемещения или установления присутствия в зонах: зоны внешней торговли могут создавать подзоны для использования отдельными компаниями в этом районе, аналогично «свободным точкам». Существует более 500 утвержденных подзон, которые могут осуществлять производственную деятельность. Крупнейшие отрасли, которые в настоящее время используют эти процедуры, включают нефтепереработку, автомобилестроение, электронику, фармацевтику, а также машины и оборудование [9].
В Европейском союзе (ЕС) государствам-членам разрешено определять части таможенной территории Союза в качестве свободных зон, куда товары из-за пределов ЕС могут поступать без ввозных пошлин и других сборов. Следовательно, многие свободные зоны в ЕС расположены на периферии Союза.

Некоторые беспошлинные зоны, наиболее распространенные в развитых странах, называются «свободными портами». Таким образом, это складские помещения, которые определены как необлагаемые налогом и используются для хранения ценных предметов, таких как произведения искусства, ювелирные изделия, драгоценные металлы и другие предметы роскоши. В Европе такие бесплатные порты существуют в Люксембурге, Монако и Швейцарии.

0Э3, направленные на промышленное или региональное развитие, находятся в странах Центральной и Восточной Европы (то есть в Болгарии, Литве и Польше), где программы ОЭЗ, в основном, предшествуют вступлению страны в ЕС. Европейская комиссия считает налоговые льготы в ОЭЗ государственной помощью. Все меры, которые представляют собой государственную помощь, должны быть предоставлены государством-членом для одобрения Комиссией.

В тех европейских странах, в которых действуют ОЭЗ, государственное участие в их управлении, как правило, значительно. ОЭЗ Болгарии находятся в ведении государственной компании. ОЭЗ в Чехии и Польше также находятся в государственной собственности. В Хорватии недвижимость в свободных от порта зонах в основном принадлежит правительству и находится под юрисдикцией местных портовых властей. В Словении свободной зоной Копер управляет публичная компания с ограниченной ответственностью, контрольный пакет акций которой принадлежит государству. В Швейцарии управляющая компания свободного порта Geneva Free Ports \& Warehouses - компания с ограниченной ответственностью, основным акционером которой является Женевское государство. Только свободный порт в Люксембурге находится в частной собственности [10]. 
Стоит отметить, что потеря статуса свободной зоны не означает, что эти зоны перестают работать. Например, Шеннон, которая повсеместно считается первой современной ОЭЗ, больше не предлагает специальных налоговых льгот или режима регулирования, отличного от остальной Ирландии, но продолжает привлекать бизнес. В свободной зоне Шеннон работает 170 компаний, в которых трудится около 8000 человек. Помимо формирования крупнейшего в Ирландии авиационно-космического кластера, ирландские и многонациональные компании инвестировали в ряд других отраслей, включая медицинские приборы, высокоинтеллектуальные технологии, ИКТ, финансовые услуги и производство электрических и легковых автомобилей.

\section{Мониторинг и оченка Аеятельности ОЭЗ}

В Российской Федерации Правительство осуществляет мониторинг и оценку ОЭЗ в разрезе их четырех типов. Закон устанавливает шесть показателей эффективности ОЭ3: инвестиционная привлекательность, бизнес-среда, инфраструктурное обеспечение, доступность земельных ресурсов, инвестиционная активность резидентов ОЭЗ и информационная прозрачность веб-сайта ОЭЗ [11]. Оценка проводится ежегодно и выдает рейтинг зон по критериям. Этот процесс служит, главным образом, для того, чтобы создать давление на неэффективные зоны и региональные органы власти, на территории которых они функционируют. Благодаря осуществлению данной оценки последовательно были выявлены неэффективные зоны и исключены из списка ОЭЗ путем их закрытия. Используя этот механизм, в период между 2010 и 2017 гг. были закрыты 11 зон [12].

В пересмотренной резолюции 2018 г., в которой была принята система более обширной оценки воздействия, добавлены четыре блока оценки:

- показатели деятельности резидентов ОЭЗ;

- эффективность федеральных, субнациональных и местных инвестиций в инженерное, транспортное, социальное, инновационное и другое инфраструктурное обеспечение ОЭ3;

- эффективность деятельности органов управления ОЭЗ;

— эффективность планирования создания ОЭЗ.

Эти общие показатели состоят из 18 подпоказателей. Методология оценки дифференцирована по типу зоны. Стоит заметить, что на сегодняшний день лишь немногие страны систематически оценивают эффективность зон, и еще меньше стран имеют механизмы для борьбы с недостаточной их эффективностью.

Эфффективность функционирования. Условия эффективности функционирования отдельных ОЭЗ включают в себя множество преимуществ в плане местоположения, только некоторые из которых определяются или могут зависеть от государственной политики. Ориентируясь на те из них, которые зависят от активных политических решений, первой и наиболее важной особенностью является выбор месторасположения [13]. Для политики ОЭЗ характерна специальная направленность на содействие экономическому развитию конкретных регионов, например, районов с высоким уровнем безработицы. Одновременно, стратегическое расположение в непосредственной близости ключевых узлов инфраструктуры (например, портов и аэропортов) и рядом с рабочими пулами имеет основополагающее значение для привлечения инвесторов в зону. Ряд проведенных исследований свидетельствует о том, что близость к портам или крупным городам стимулирует темпы развития зон с большей вероятностью, чем размещение ОЭЗ в более отдаленных районах. Так, во многих развивающихся странах с одной или очень немногими крупными городскими агломерациями расстояние до крупнейшего города отрицательно коррелирует с показателями зоны, что указывает на то, что ОЭЗ вероятно могут являться неэффективным инструментом развития отдаленных или относительно бедных регионов. Преференции, предоставляемые в зонах, обычно считаются ключевым элементом эффективности функционирования таких территорий. Тем не менее, использование обширных пакетов различных льгот и стимулов для компенсации локальных недостатков может быть неэффективным. Проведенный анализ не обнаружил корреляции между налоговыми стимулами, предлагаемыми инвесторам, и ростом зоны с точки зрения рабочих мест и экспорта. Поэтому сами по себе стимулы недостаточны как обоснование для эффективной работы зоны. Отсутствие корреляции может быть отчасти вызвано растущей конвергенцией инвестиционных стимулов зоны и отсутствием дифференциации [14]. Стоит обратить внимание на отсутствие ряда различий в налоговых стимулах, но только на границе; большинство пакетов стимулов включают освобождение от ввозных пошлин на машины и материалы, а также снижение или освобождение от налогов. Более важным, чем предлагаемый набор стимулов, может быть упрощение административных процедур для предприятий и инвесторов в зоне посредством упорядочения и универсализации соответствующих процессов, или создания «единых окон».

\section{Bыво $\triangle$}

Изучение мирового опыта формирования особых экономических зон позволяет сделать обоснованный вывод, что их появление улучшает имидж региона и страны в целом как центра деловой активности. Особенно эффективность ОЭЗ заметна при активном участии государственных властей различного уровня в создании благоприятных условий для функционирования зон, особенно в части формирования инвестиционной поли- 
тики государства в целом.

Практика создания и функционирования территорий с особым правовым статусом в России имеет принципиально отличный от зарубежных подход. В России большинство ОЭЗ были образованы, в основном, по административно-территориальному принципу, что в принципе противоречит мировой практике программно-целевого подхода, при котором развитие некоторого количества небольших по размерам хозяйственных структур существенно содействует быстрому экономическому росту целой страны. В связи с этим представляется нецелесообразной простая адаптация мирового опыта создания и функционирования подобных территорий. Существующие механизмы и практики создания и развития таких территорий не могут быть использованы в отрыве от российской специфики и действительности (опыт создания и последующего закрытия отдельных ОЭЗ ярко продемонстрировал это), а сами же институты пространственного развития уже получили широкое применение в России.

ЛИТЕРАТУРА

1. Меджидов 3.У. Зарубежный опыт функционирования особых экономических зон // Вектор науки Тольяттинского государственного университета. Серия: экономика и управление. - 2016. - №1. - С. 55-61.

2. Смородинская Н.В. Организация особых экономических зон в мировой и российской практике: концептуальные аспекты // Вестник Института экономики Российской академии наук. - 2011. - № 3. - С. 16-36.

3. Баландина А.С., Баннова К.А., Брайченко А.А. Зарубежный опыт создания особых экономических зон в развитых странах// Проблемы учета и финансов. 2016. №4(24).

4. Фаттахов Р.В., Строев П.В. Пространственный аспект модернизации экономики России // Экономика. Налоги. Право. -2015. -№ 6. -С. 6-14.

5. Мальченко Б.С. Российский опыт функционирования особых экономических зон // в сборнике: Институциональные и инфраструктурные аспекты развития различных экономических систем. Сборник статей международной научно-практической конференции. - 2018. - C.175-178.

6. Пивоварова 0.В. Международный опыт оценки эффективности государственного управления // Государственное и муниципальное управление. Учетные записки. -2020. - № 2. - С. 80-86.

7. Морковкин Д.Е., Строев П.В., Макар С.В. Динамика трансграничных потоков капитала стран ЕАЭС: пространственный анализ // Финансовая жизнь. 2019. - № 1. - С. 34-37.

8. Иванов Г.Г., Орлов С.Л. Особые экономические территории в России: Монография (2-е издание, переработанное и дополненное). - М.: Издательско-торговая корпорация «Дашков и К», 2019. -252 с.

9. Шабалина Т.А. особые экономические зоны как фактор комплексного развития российских регионов // Экономика и предпринимательство. - 2018. №1. - C. 302-305.

10. Макар С.В. Ключевые структуры пространственного развития России и ее регионов: современные акценты // В сборнике: Пространственный потенциал развития России: невыученные уроки и задачи на будущее. Сборник научных трудов участников Международной научной конференции - XXVI Кондратьевский чтения. - 2019. С. 234-236.

11. Низамутдинов М.М., Орешников В.В. Пространственная мобильность населения России // Известия Уфимского научного центра РАН. - 2019. - №3. C. 61-68.

12. Васильева И.А. Территории с особым статус в экономической системе страны // 0economia et Jus. - 2018. - №1. - С. 1-6.

13. Морковкин Д. Е. Современные инструменты пространственного регулирования ускоренного социально-экономического развития России // Муниципальная академия. - 2017. - № 2. - С. 25-36.

14. Аксенов М.А., Журавлева О.В., Меньщикова В.И. Модель развития особых экономических зон в России // Ученые записки Российской Академии предпринимательства. - 2018. - Т.17. - №1. - С. 9-

(c) Фаттахов Рафаэль Валиахметович (RFattakhov@fa.ru), Пивоварова Ольга Владимировна (olga_piv@mail.ru), Морковкин Дмитрий Евгеньевич (DEMorkovkin@fa.ru). 